\title{
Thoughts on the Book Nuclear Reactor Safety
}

\author{
CSURGAI József ${ }^{1}$, SOLYMOSI Máté2
}

\begin{abstract}
In 2013 December, the SOMOS Environmental Protection Ltd. and the ELTE Eötvös Publishing Company published a new book dedicated to the safety of nuclear reactors and having analogous title ("Nuclear reactor safety"). For the readers of Academic and Applied Research in Military Science we want to present some considerations for reviewing the book.
\end{abstract}

Keywords: nuclear reactor safety, operation and construction of nuclear reactors, safe operation, safety assessment, legal regulation of the reactor safety

\section{Introduction}

Nuclear weapons, defense against them and the non-proliferation issues have priorities in military science and the science of military engineering. Military tasks of nuclear emergency response and the research with contemporary scientific tools are especially important to meet the challenge of the renaissance of CBRN weapons.

The book on Safety of Nuclear Reactors is closely connected to the previously mentioned military and defensive tasks. It provides complete theoretical and practical knowledge of nuclear safety, one of the most essential parts of military engineering, i.e. the safety of nuclear reactors and nuclear power plants, including response tasks of a nuclear emergency.

The book Nuclear Reactor Safety covers the issues of the peaceful use of nuclear energy, and of the safe construction and operation of nuclear power plants. [1] The following goals of the book were declared by the editors: to complement missing basic knowledge, knowledge transfer, to awaken interest and support experts.

1 csurgai.jozsef@uni-nke.hu

2 mate.solymosi@somos.hu 


\section{Volume I. of Nuclear Reactor Safety}

The Book has 750 pages in two volumes. The 378 pages of the first volume are separated into Chapters I-III. The contents of the chapters are shortly summarized below.
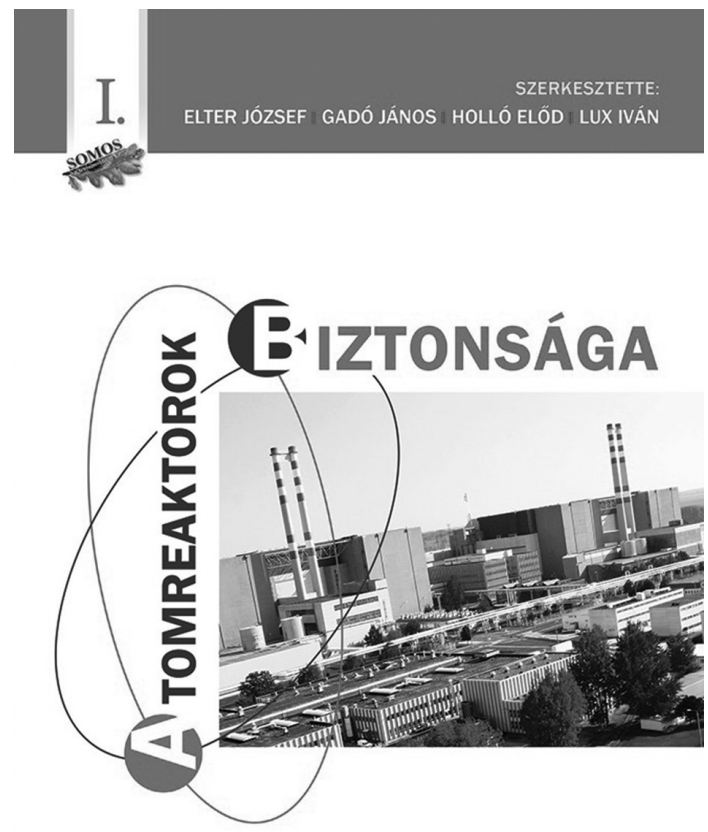

Picture 1. The cover of Volume I.

\section{Chapter I. The most important processes of nuclear reactors}

The first chapter reviews the basic nuclear processes facilitating the understanding of the following chapters: fission, chain-reaction, neutron physics, critical systems, research reactors, nuclear power plants, the basic physics of the pressurized water reactors, and the basics of thermo hydraulics, fuel cycle, the behaviour of fuel elements, activity transport and environmental effects.

\section{Chapter II. The construction of nuclear power plants}

This chapter reviews the basic operation of a nuclear power plant, the function of a nuclear power plant, the features of the power plant cycle, the main characteristics of systems and equipment. 


\section{Chapter III. The basics of reactor design safety}

The subjects of the chapter are the normal and emergency operational conditions, and the design basis of them; incidents, accidents, safety functions and systems; design basis and deterministic design principles, risks and characteristics and criteria of risk.

\section{Volume II. of Nuclear Reactor Safety}

The 372 pages of the second volume are separated into Chapters IV-VI.
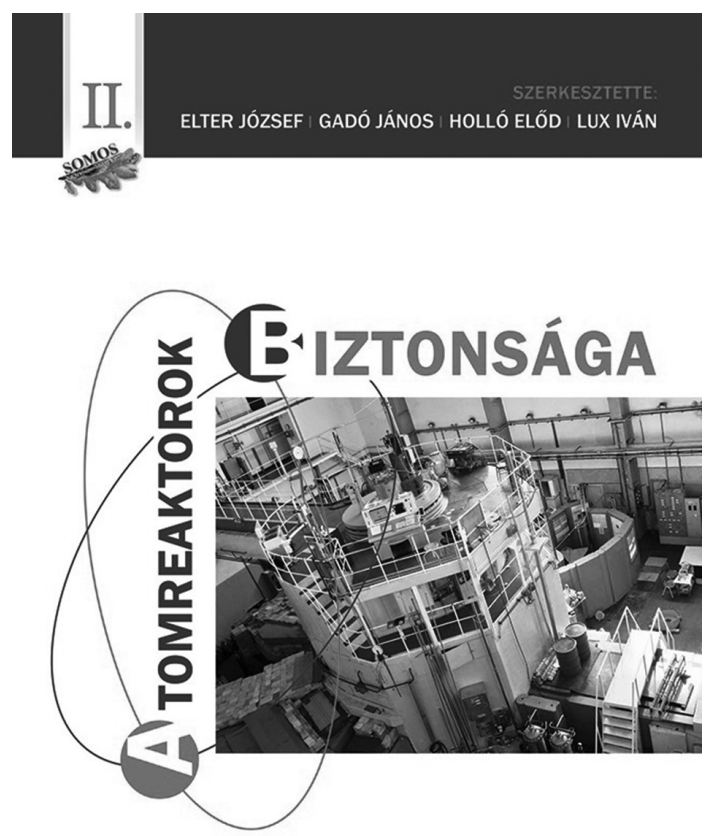

Picture 2. The cover of Volume II.

\section{Chapter IV. The operational safety of the reactors}

Beside the technical requirements, the safety culture and the operational norms, for the consistency and coherence for the construction and the safe operation of a nuclear reactor there must be established instructions and procedures described in the actual chapter. The chapter shows how these norms, instructions and procedures must be complied with in any circumstances during normal and emergency operation. The aging treatments, maintenance, monitoring and testing listed in the chapter are also important elements of safe operation as long as possible. 


\section{Chapter V. The basics of safety assessments}

The chapter depicts how safety assessment demonstrates the acceptability of safety level resulting from control measurements and tests directed at serious accident assessments, Level 1 and Level 2 PSA, assessments of external hazards and the evaluation of source term, activity transport and health effects.

\section{Chapter VI. The legislation for the safety of nuclear reactors}

The acceptance of the use of nuclear reactors in society is - as usual - based on legal regulations.

The relevant legislation is mostly based on international standards and other norms accepted by international organizations. Among these are the safety standards of the IAEA ${ }^{3}$ [3] and the European Union regulations, directives and recommendations. Safety is guaranteed by the international organizations and a system of international conventions.

The chapter describes the legislative background, the responsibilities, safety reports, and the activity of international organizations (IAEA, OECD ${ }^{4} \mathrm{NEA}^{5}$, ENSREG $^{6}$, WENRA ${ }^{7}$ ) and the system of international conventions.

\section{Final conclusions}

The Hungarian authors of the book have published such a complex work on the topic, a first in the world. Besides the theoretical questions the book provides an overview of the process how the issues of nuclear reactors' safety are handled by professionals in practice. It can be stated that the book is a new and bright lighthouse in the sea of domestic nuclear safety. It directs and guides the reader through the safety issues of the electricity-producing nuclear power plants, which make up the dominant part of the peaceful use of nuclear energy.

Besides the importance, the actuality of the book is also acknowledged, because the $\mathrm{MVM}^{8}$ Paks Nuclear Power Plant (NPP) has a leading position in energy production in Hungary, generating more than $40 \%$ of the domestic electric energy. However, the increase in energy production has become a necessity recently, and one of the important and environmentally friendly ways is the extension of the Paks Nuclear Power Plant with a new block or blocks. Young specialists, as well as students, teachers and workers in their field of work can find knowledge and experience in the book necessary for the NPP's extension. A well of experience and several decades of practical knowledge from the writers were also incorporated into this masterpiece.

Holló Előd, one of the editors of the book mentioned the possibility of a shorter English edition of the book.

The book has 24 authors, who are not teachers, but experts in their own fields, acknowledged both at a domestic and international level. The diversity results in the occasional struc-

3 International Atomic Energy Agency

4 The Organisation for Economic Co-operation and Development

5 Nuclear Energy Agency

6 European Nuclear Safety Regulators Group

7 Western European Nuclear Regulators Association

8 MVM - Magyar Villamos Művek (Hungarian Electric Energy Corporation) 
tural problems of the book. It is not a lack of teaching approach, rather the missing unified approach and style that might be objected to.

The editors sought homogeneity with the main objectives, that the principles must be reviewed generally and the practical implementations with examples from the Paks NPP should also be referred to. The four-member editorial board had a difficult task to ensure a homogeneity of visions of 24 individual authors. It is appreciated that their effort was mostly successful, but not in every case, unfortunately.

We hope that these imperfections of the Hungarian edition will be eliminated in the planned English edition and the readers will receive a great handbook.

Based on all these, we highly recommend this book for the specialists of both the civil and the defense sectors.

\section{References}

[1] ELTER, J., GADÓ, J., HOLLÓ, E., LUX, I. (Eds.): Atomreaktorok biztonsága I., II. kötet. (Safety of Nuclear Reactors, Volume I. and II.) (in Hungarian), Budapest: Somos Environmental Protection Ltd., ELTE Eötvös Publisher, 2013. ISBN 978312180 1, and ISBN 9783121825

[2] IAEA: IAEA Safety Standards Series. Vienna, 2008. http://www-pub.iaea.org/mtcd/ publications/sss.asp (downloaded: 2112 2013)

[3] MTA: A nukleáris biztonság területén elért kutatási eredményeket ismertek el az Akadémián. MTA hírek. Budapest: MTA, 2013. 05. 06 http://mta.hu/mta_hirei/a-nuklearis-biztonsagteruleten-elert-kutatasi-eredmenyeket-ismertek-el-az-akademian-131876/ (downloaded: 21 12 2013) 